\title{
Características físico-químicas e atividade antimicrobiana de extratos de própolis da Paraíba, Brasil
}

\author{
Physicochemical characteristics and antimicrobial activity of the extracts propolis of the \\ Paraiba, Brazil
}

\author{
Rosilene Agra da Silva ${ }^{1}$ Adriana Evangelista Rodrigues ${ }^{2}$ \\ Maria Cristina Marcucci Ribeiro ${ }^{3}$ Ângela Ramalho Custódio ${ }^{3}$ \\ Norma Estefânia Domingues Andrade ${ }^{4}$ Walter Esfraim Pereira ${ }^{5}$
}

\section{RESUMO}

Objetivou-se com esta pesquisa analisar a própolis produzida por abelhas Apis mellifera L. no Estado da Paraíba, colhida pelo método de tela plástica, determinando-se a composição físico-química e a atividade antimicrobiana conforme o período de colheita das amostras. Para a determinação físico-química, foram avaliados os teores de umidade, cinzas, resíduos insolúveis, cera, sólidos solúveis, fenóis, flavonóides e índice de oxidação. Para o estudo da atividade antimicrobiana, foram utilizados os microrganismos Candida albicans e Staphylococcus aureus. O teor de umidade, os resíduos insolúveis, as cinzas, os sólidos solúveis, os fenóis, os flavonóides e o índice de oxidação das amostras testadas apresentaram uma variação de 1,0 a 8,6\%; 23,5 a 40,4\%; 1,1 a 3,3\%; 32,0 a 62,5\%; 1,0 a 8,1\%; 0,04-0,5\% e de 14 a 29 segundos, respectivamente. Os extratos etanólicos de própolis não apresentaram inibição ao crescimento dos patógenos testados. Observou-se, também, que a própolis colhida em diferentes épocas do ano, assim como a própolis oriunda de diferentes colméias, apresentaram diferentes valores para a composição bromatológica e bioativa, tendo a própolis amostrada nos períodos de maior precipitação os melhores valores para compostos bioativos.

Palavras-chave: flavonóides, abelhas, própolis, ação antimicrobiana.

\section{ABSTRACT}

This study was aimed at analysing the propolis produced in beehive of Apis mellifera L. bee in the state of Paraiba - Brazil. Propolis was collected by the method of plastic screen, determining the physical-chemical composition and antimicrobial activity according to the period of collection of the samples. For the physical-chemical determination, it was assessed the humidity, ashes, insoluble residues, wax, soluble solids, phenols, flavonoids and oxidation index. To study the antimicrobial activity, microorganisms Candida albicans and Staphylococcus aureus were used. The humidity contents, insoluble residues, ashes, soluble solids, phenols, flavonids and index of oxidation of the tested propolis varied from 1.03 to $8.58 \%$; 23.47 to $40.38 \%$; 1.13 to $3.25 \%$; 31.97 to $62.54 \% ; 1.01$ to $8.13 \%$; $0.045-0.52 \%$ and from 14 to 29 seconds, respectively. None of the etanol extracts of propolis inhibited the growth of bacteria pathogenic. It was also observed that the propolis collected in different times of the year, as well as propolis originated from of different beehives, showed different chemical composition and bioactive and that propolis sampled in periods of greater precipitation had better values of bioactive compounds.

Key words: flavonoids, bees, propolis.

\section{INTRODUÇÃO}

A própolis é uma substância resinosa colhida pelas abelhas melíferas de diferentes exudatos de plantas, tais como secreções de árvores, folhas e flores. Esta resina é utilizada pelas abelhas na proteção da colméia contra a proliferação de microrganismos, incluindo fungos e bactérias.

Este produto apícola tem sido utilizado na medicina popular de inúmeros países, por suas atividades biológicas, podendo-se citar atividades

'Programa de Pós-graduação em Zootecnia, Universidade Federal da Paraíba (UFPB), Centro de Ciências Agrárias (CCA), Areia,

Paraíba, Brasil. E-mail: rosileneagra@ hotmail.com

2Departamento de Zootecnia, UFPB, CCA, 58397-000, Areia, PB, Brasil. E-mail: adrievan@terra.com.br

${ }^{3}$ Laboratório Naturalab, Campinas, SP, Brasil.

${ }^{4}$ Universidade Bandeirantes (UNIBAN), São Paulo, SP, Brasil.

${ }^{5}$ Departamento de Ciências Fundamentais e Sociais, UFPB, CCA., Areia, PB, Brasil. 
antimicrobianas, antiinflamatórias, anti-sépticas, entre outras, que tem recentemente atraído a atenção dos pesquisadores pela riqueza química (GHISALBERTI, 1979, AGA et al., 1994; BANKOVA et al., 1995; MARCUCCI, 1995; SFORCIN etal., 1998; FERNANDES JÚNIOR et al., 1998).

Visto que no Brasil a colheita de própolis pode se dar durante todo o ano, não são raras as possíveis variações sazonais em sua composição e atividade, considerando-se a região e o local de colheita onde a própolis foi produzida (LABBE et al., 1986; SFORCIN et al., 1998).

De uma maneira geral, a composição da própolis inclui 55\% de resinas e bálsamos, $30 \%$ de cera, $10 \%$ de pólen e metabólitos secundários, incluindo flavonóides, ácidos fenólicos, além de minerais (MATSUNO, 1995; MIYATAKA et al., 1997). Já foram identificados mais de 200 compostos em amostras diferentes, incluindo ácidos fenólicos e seus ésteres, flavonóides (flavonas, flavononas, flavonóides, chalconas) e terpenos, ( $\beta$-esteróides, aldeídos aromáticos e álcoois, sesquiterpenos, naftaleno e derivados do estilbeno) (GREENAWAY et al., 1990; AGA et al.,1994; BANKOVA et al., 1995; MARCUCCI et al., 1995).

Devido à grande variabilidade da flora brasileira, a composição química da própolis é extremamente complexa, existindo também diferenças entre a própolis produzida por abelhas nativas e abelhas africanizadas (Apis mellifera L.). Diante destas informações, objetivou-se analisar a própolis produzida por abelhas africanizadas no Estado da Paraíba, para a determinação da composição físico-química e da atividade antimicrobiana de acordo com o período de colheita das amostras.

\section{MATERIAL E MÉTODOS}

As amostras de própolis para análise foram colhidas de colméias de Apis mellifera L., do tipo Langstroth, instaladas no Apiário do Centro de Ciências Agrárias em Areia - PB do Departamento de Zootecnia da Universidade Federal da Paraíba. A cidade de Areia está localizada na Microrregião do Brejo Paraibano, ficando a 618 metros acima do nível do mar. O município possui um clima uniforme e ameno, com temperaturas variando de $15^{\circ}$ a $30^{\circ} \mathrm{C}$, umidade relativa de 80\% (ENCICLOPÉDIA DOS MUNICÍPIOS, 1987) e precipitação média anual podendo chegar a $1.300 \mathrm{~mm}$, sendo que, no período de estudo (julho de 2001 a maio de 2002), a temperatura variou de 20,7 a $23,5^{\circ} \mathrm{C}$ e a precipitação variou de 148,1 a 160,8mm. O clima da região é quente e úmido, com chuvas no período de outonoinverno (VELOSO JÚNIOR, 2000).

Para a colheita da própolis, foram utilizadas telas plásticas colocadas sob as tampas das colméias, que periodicamente eram revisadas, acondicionadas em freezer por 24 horas. Por fricção, retirou-se a própolis da tela, armazenando-a em potes devidamente etiquetados.

As análises físico-químicas e microbiológicas foram realizadas no Laboratório Naturalab - Análises e Pesquisas Ltda (Campinas - SP) e na Universidade Bandeirantes - UNIBAN (São Paulo - SP), utilizando a metodologia de determinação de acordo com SILVA (1998).

Especificações das Análises Físicas da Própolis

Para as análises físico-químicas da própolis, foram realizadas triplicatas para obtenção dos resultados. Para análise de umidade, pesou-se aproximadamente $1,0 \mathrm{~g}$ de cada amostra em vidro relógio, com um total de 21 amostras. Depois de pesadas, as amostras foram levadas à estufa $\left(70^{\circ} \mathrm{C} / 1\right.$ hora (Quimis 317B243), repetindo-se o procedimento até obter-se peso constante. Em relação a cinzas, 2,0g das amostras de própolis foram pesados em cadinho, e, para cada amostra de própolis, foram feitas triplicatas. Em seguida, os cadinhos foram levados à mufla (Quimis Q-318M24) até alcançar temperatura de $600^{\circ} \mathrm{C}$, deixando-se ali por aproximadamente uma hora. Com os dados, calculouse a porcentagem de cinzas. Para a determinação dos valores de resíduos insolúveis, sólidos solúveis e cera, procedeu-se à extração em aparelho tipo Soxhlet. Em um cartucho, feito com papel de filtro de peso conhecido, após secagem em estufa (Quimis 317B243), pesou-se aproximadamente $10,0 \mathrm{~g}$ da amostra de própolis e colocou aparelho Soxhlet, para extração com álcool de cereal por 24 horas. Ao término do processo, o precipitado obtido da extração em Soxhlet foi colocado em Becker, esfriado à temperatura ambiente e levado à geladeira para posterior filtragem em funil de Buchner forrado com papel filtro apropriado. Logo após isso, o precipitado da filtragem foi lavado com etanol gelado, até obter-se um resíduo branco no papel filtro. O resíduo que ficou no papel filtro foi secado em estufa a $40^{\circ} \mathrm{C}$ por aproximadamente 24 horas. Por diferença, encontrou-se o teor de cera da amostra. Após a extração da cera, o cartucho com o resíduo foi levado para estufa a $40^{\circ} \mathrm{C}$ por 24 horas, efetuando-se a pesagem, em seguida, em balança analítica. $O$ filtrado da extração da cera foi medido em proveta de $500 \mathrm{~mL}$ e guardado em vidro de cor âmbar. Em um Becker de peso conhecido, adicionou-se uma alíquota de 5,0mL (Va) do extrato da própolis que foi filtrado, seguido de secagem em estufa 
a $60^{\circ} \mathrm{C}$. Foi encontrado pelo método gravimétrico o valor de sólidos solúveis em etanol. Com o filtrado dos sólidos solúveis em etanol, procedeu-se às análises de fenóis, flavonóides e índice de oxidação, como descrito a seguir: Em um becker de $100 \mathrm{~mL}$, foram pipetados $2 \mathrm{~mL}$ do extrato e adicionados $48 \mathrm{~mL}$ de água destilada, sendo agitados com bastão de vidro. Em um tubo de ensaio de $15 \mathrm{~mL}$, previamente lavado com solução sulfocrômica e seco, foram pipetados $0,5 \mathrm{~mL}$ do diluído, $0,5 \mathrm{~mL}$ de água destilada, $1 \mathrm{~mL}$ de ácido sulfúrico a $20 \%$, misturando-os bem e resfriando-os em banho de gelo até obterem a temperatura de $18^{\circ} \mathrm{C}$. Em seguida, com auxílio de uma micropipeta, foram acrescentados $50 \mathrm{~mL}$ de $\mathrm{KMnO}_{4}$ 0,1 $\mathrm{N}$ e ligado o cronômetro, observando o desaparecimento da cor vermelha contra um fundo branco, anotando-se o tempo decorrido. O teste foi feito em duplicata. $\mathrm{O}$ valor médio encontrado foi anotado, desprezando-se a fração, quando houve.

A análise quantitativa e qualitativa dos fenóis do extrato etanólico de própolis (EEP) foi realizada por determinação de fenóis totais em espectrofotometria na região ultravioleta (UV scanning). Para tanto, foi utilizado o método espectrofotométrico, que se baseia no método de FollinCiocalteau. A análise quantitativa e qualitativa dos flavonóides do EEP foi realizada por determinação de flavonóides totais em espectrofotometria na região ultravioleta (UV scanning) e cromatografia líquida de alta eficiência (CLAE). As análises foram feitas pelo método espectrofotométrico, expressados em quercentina para leitura em $425 \mathrm{~nm}$, de acordo com o método descrito na Farmacopéia Alemã e na dissertação publicada por Gomide, em 1926, citado por MARCUCCI eCUSTÓDIO (2002).

Os Extratos Etanólicos de Própolis (EEP) das amostras foram preparados a $30 \%$ para realização posterior dos estudos microbiológicos.

$\mathrm{Na}$ análise de identificação da atividade antimicrobiana, utilizaram-se discos de papel de filtro Whatman n.3 (5x1mm de diâmetro), onde foram aplicados $3 \mathrm{~mL}$ dos respectivos extratos de própolis e então colocados em placas de Petri para secar em estufa a $60^{\circ} \mathrm{C}$, por aproximadamente 15 minutos, para eliminação de qualquer resíduo etanólico. As culturas ativadas de Staphylococcus aureus e Candida albicans foram inoculadas por espalhamento com "swabs" estéreis em placas de Petri contendo ágar nutriente. Os discos com os extratos foram colocados sobre as placas inoculadas e incubadas a $37^{\circ} \mathrm{C}$ por 24 horas. Para o tratamento controle, foram inoculadas placas com as culturas ativadas das bactérias, não recebendo o disco com extrato de própolis. A atividade antimicrobiana foi determinada pela formação ou não de halo inibitório ao redor dos discos.

Foi aplicado um delineamento inteiramente casualisado para cada característica das amostras de própolis analisadas, sendo que cada característica teve três repetições. O teste Tukey foi utilizado na comparação entre as médias dos tratamentos de cada característica (umidade, cinzas, sólidos em etanol, fenóis e flavonóides). Foi empregada uma análise multivariada, utilizando-se o software SAEG (2000), versão 8.0.

\section{RESULTADOS E DISCUSSÃO}

A tabela 1 apresenta os valores médios encontrados dos parâmetros estudados para todas as amostras. As colheitas 1, 2 e 3 retiradas da mesma colméia com variação no período apresentaram diferenças para todos os parâmetros estudados, mostrando a interferência direta da estação do ano sobre as características do produto. A colheita 1 foi realiza no período de julho a setembro de 2001, período este de maior precipitação pluviométrica do que os períodos em que foram realizadas as colheitas 2 e 3 . No entanto, os valores de umidade da própolis apresentaram-se como $2,78 \%, 1,94 \%$ e $2,31 \%$, respectivamente, mostrando que não houve influência da precipitação pluviométrica sobre os valores de umidade, tanto que a amostra da colheita 1 não diferiu estatisticamente da amostra da colheita 3 . As diferenças encontradas nos parâmetros para as colheitas 1, 2 e 3 são explicadas pela diversidade de plantas visitadas pelas abelhas para a colheita de resinas na fabricação de própolis, nos diferentes períodos do ano.

Para os valores de sólidos em etanol e fenóis totais, a amostra da Colheita 1 foi a que apresentou melhor resultado, cujos valores são respectivamente 62,54 e $8,13 \%$, seguidas pelas amostras da Colheita 6 (52,62\% para sólidos solúveis e 5,18\% para fenóis) e Colheita 4 (47,93\% para sólidos solúveis e 5,02\% para fenóis) $(\mathrm{P}<0,05)$. Verificando-se, na tabela 1 , os valores de cinzas, fenóis e resíduos insolúveis das amostras de própolis colhidas, observa-se que todos os valores encontrados para as colheitas estão de acordo com a Legislação Vigente (BRASIL, 2002). GARCIA et al. (2001), analisando a própolis do Paraná, encontraram valores para cinzas (3,56\% no verão e $3,20 \%$ no inverno) maiores do que o encontrado neste trabalho $(1,13 \%$ no verão e $1,14 \%$ no inverno).

Comparando-se os dados colhidos das amostras de própolis deste trabalho com os valores da Legislação Vigente (BRASIL, 2002), constatou-se que 
Tabela 1 - Valores médios das análises físico-químicas das amostras de própolis, de acordo com o período de colheita, e a absorbância dos extratos etanólicos de própolis para a determinação de fenóis e flavonóides.

\begin{tabular}{|c|c|c|c|c|c|c|}
\hline $\begin{array}{l}\text { Parâmetros } \\
\text { analisados }\end{array}$ & $\begin{array}{l}\text { Colheita } 1 \\
\text { (julho a } \\
\text { setembro de } \\
\text { 2001) }\end{array}$ & $\begin{array}{c}\text { Colheita } 2 \\
\text { (setembro a } \\
\text { dezembro de } \\
\text { 2001) }\end{array}$ & $\begin{array}{l}\text { Colheita } 3 \\
\text { (dezembro de } \\
2001 \text { a janeiro } \\
\text { de 2002) }\end{array}$ & $\begin{array}{l}\text { Colheita } 4 \\
\text { (dezembro de } \\
2001 \text { a janeiro } \\
\text { de 2002) }\end{array}$ & $\begin{array}{c}\text { Colheita } 5 \\
\text { (dezembro de } \\
2001 \text { a fevereiro } \\
\text { de 2002) }\end{array}$ & $\begin{array}{c}\text { Colheita } 6 \\
\text { (fevereiro a } \\
\text { maio de 2002) }\end{array}$ \\
\hline Umidade (\%) & $2,78 \mathrm{c}$ & $1,94 \mathrm{~b}$ & $2.31 b c$ & $1,95 \mathrm{~b}$ & $1,03 \mathrm{a}$ & $2,88 \mathrm{c}$ \\
\hline Cinzas (\%) & $1,42 b$ & $1,13 \mathrm{a}$ & $1,25 \mathrm{ab}$ & $1,70 \mathrm{c}$ & $1,33 \mathrm{ab}$ & $1,14 \mathrm{a}$ \\
\hline $\begin{array}{l}\text { Resíduos } \\
\text { Insolúveis (\%) }\end{array}$ & 31,08 & 24,40 & 29,11 & 28,52 & 29,09 & 23,47 \\
\hline Cera $(\%)$ & 12,25 & 38,55 & 38,05 & 23,06 & 30,49 & 15,69 \\
\hline $\begin{array}{l}\text { Sólidos } \quad \text { em } \\
\text { Etanol }(\%)\end{array}$ & $62,54 \mathrm{a}$ & $40,77 \mathrm{de}$ & $38,33 \mathrm{e}$ & $47,93 \mathrm{bc}$ & $43,19 \mathrm{~cd}$ & $52,62 b$ \\
\hline Fenóis (\%) & $8,13 \mathrm{a}$ & $2,93 \mathrm{f}$ & $3,45 \mathrm{~d}$ & $5,02 \mathrm{c}$ & $3,25 \mathrm{e}$ & $5,18 \mathrm{~b}$ \\
\hline $\begin{array}{l}\text { Flavonóides } \\
(\%)\end{array}$ & $0,38 \mathrm{~b}$ & $0,38 \mathrm{~b}$ & $0,19 d$ & $0,52 \mathrm{a}$ & $0,36 \mathrm{~b}$ & $0,27 \mathrm{c}$ \\
\hline $\begin{array}{l}\text { Atividade } \\
\text { antioxidante } \\
\text { (seg.) }\end{array}$ & 22 & 23 & 22 & 14 & 20 & 29 \\
\hline $\begin{array}{l}\text { Absorbância } \\
\text { dos Fenóis }\end{array}$ & 0,470 & 0,213 & 0,269 & 0,312 & 0,224 & 0,293 \\
\hline $\begin{array}{l}\text { Absorbância } \\
\text { dos Flavonóides }\end{array}$ & 0,019 & 0,028 & 0,014 & 0,033 & 0,025 & 0,015 \\
\hline
\end{tabular}

Médias seguidas da mesma letra na mesma linha não diferem entre si pelo teste de Tukey em nível de 5\% de probabilidade.

os resultados obtidos para o teor de cera mostram que a própolis das Colheitas 2, 3, e 5 não estão de acordo com o exigido, pois apresentam, respectivamente, $38,55 \%, 38,05 \%$ e $30,49 \%$ de cera, percentagens , que estão acima do permitido, que é de $25 \%$ de cera. Porém, a própolis das Colheitas 1, 4 e 6 apresentaram valores dentro do permitido pela Legislação, ou seja, apresentaram 12,25\%,23,06\% e 15,69\% de cera. GARCIA et al. (2001) encontraram altos teores de cera analisando a própolis do Paraná, que corresponderam à colheita no verão 26,72 ( 6,26 e no inverno 25,08 (4,58, estando acima do permitido pela Legislação Vigente (máximo de 25\%). As amostras das Colheitas 2, 3, 4, e 5, que apresentaram as maiores concentrações de cera $(38,55 \%, 38,05 \%, 23,06 \%$ e $30,49 \%$, respectivamente), são amostras colhidas na época do verão, período em que ocorre precipitação média e baixa na região.

Os dados encontrados neste trabalho sugerem que as abelhas, durante o período das
Colheitas 2, 3, 4 e 5, em que foi encontrada maior quantidade de cera, à medida que encontraram escassez de resina no campo, começaram a aumentar a proporção de cera na própolis produzida durante aquele período. Entretanto, quando encontraram novas fontes de resina, diminuíram o teor de cera na produção da própolis, como aconteceu com os valores para as Colheitas 1 e 6 (final do inverno e começo de inverno, respectivamente). Para a atividade antioxidante da própolis, os valores encontrados para a Colheita 2 (>22seg ( 23seg) e para a Colheita 6 (>22seg ( 29seg) ultrapassaram os 22 segundos exigidos pela Legislação, indicando que apenas as colheitas 1, 3, 4 e 5 apresentaram atividade antioxidante com os respectivos valores (22 segundos, 22 segundos, 14 segundos e 20 segundos) (Tabela 1). De acordo com a literatura, a atividade antioxidante dos extratos etanólicos e aquoso de própolis são conferidos aos flavonóides (PRATT \& WATTS, 1964; HAMMERSCHMIDT \& PRATT, 1978; PRATT \& BIRAC, 1979). 
Como pode ser observado na tabela 1 , o teor de flavonóides totais presente nas amostras de própolis das Colheitas 1, 2, 3, 4, 5 e 6, respectivamente $0,38 \%, 0,38 \%, 0,19 \%, 0,52 \%, 0,36 \%$ e $0,27 \%$, não estão de acordo com as exigências da Legislação, cujo valor fixo é de, no mínimo, $5 \%$ de flavonóides (BRASIL, 2002). Como o método empregado neste trabalho utiliza o solvente metanol como diluente do extrato seco das própolis, supõe-se que a baixa solubilidade em metanol das amostras de própolis estudadas tenha sido o fator limitante do baixo teor de flavonóides arrastados por este solvente. FRANCO \& KUREBAYASHI (1986) verificaram, em soluções alcoólicas de própolis, teor elevado de flavonóides, variando de 0,24 a $7,5 \mathrm{~g} 100 \mathrm{~mL}^{-1}$, enquanto que, quando trabalharam com soluções hidroalcoólicas, os teores de flavonóides ficaram entre 0,007 e $0,050 \mathrm{~g} 100 \mathrm{~mL}^{-1}$. Estatisticamente, a $5 \%$ de probabilidade pelo teste de Tukey, a amostra de própolis da Colheita 4 apresentou o melhor resultado $(0,52 \%$ de flavonóides), seguida pelas amostras das Colheitas 1 , 2 e 5 (respectivamente $0,38,0,38$ e $0,36 \%$ de flavonóides).

GARCIA et al. (2001), analisando própolis do Paraná colhidas no período do verão e do inverno, encontraram valores para teor de flavonóides de 5,33\% e $3,73 \%$, respectivamente. No presente estudo, o teor de flavonóides das amostras de própolis colhidas no inverno variou entre $0,27 \%$ e $0,38 \%$, enquanto que, no verão, teve uma variação de $0,19 \%$ a $0,52 \%$. PARK et al. (2001) observaram que, na análise dos flavonóides existentes na própolis do Sul do Brasil, da Argentina e do Uruguai, todas apresentaram os mesmos flavonóides, variando somente a proporção, o que sugere a mesma fonte vegetal para a origem botânica dessas própolis. Isto pode ser explicado em parte pela variação climática, o que pode causar uma certa oscilação na proporção dos componentes da fonte vegetal primária em cada estação do ano.

As amostras das Colheitas 1 e 6 formam um grupo que apresentam altos teores de fenóis $(8,13$ e $5,18 \%$, respectivamente), sólidos solúveis (62,5 e 52,6\%, respectivamente) e teores médios de flavonóides $(0,38$ e $0,27 \%$, respectivamente), sendo estas as variáveis responsáveis pelo agrupamento destas amostras de própolis (Figura 1). Isso indica excelentes amostras, já que eles são os compostos bioativos responsáveis pela atividade biológica da própolis. As amostras das colheitas 2, 3, 4 e 5 formam um grupo com características semelhantes às do grupo anterior. Apresentaram maiores teores de flavonóides $(0,4 \%, 0,2 \%, 0,5 \%$ e $0,6 \%$, respectivamente) e teores intermediários de fenóis $(2,93 \%, 3,45 \%, 5,02 \%$ e $3,25 \%$, respectivamente), sólidos solúveis $(40,77 \%, 38,33 \%, 47,93 \%$ e 43,19\%, respectivamente) e umidade $(1,94 \%, 2,31 \%, 1,95 \%$ e $1,03 \%)$. Porém, estatisticamente, este grupo de amostra de própolis diferencia-se do grupo anterior porque as variáveis responsáveis pelo agrupamento destas amostras foram a cera e a precipitação pluviométrica, apresentando maior quantidade de cera $(38,55 \%$, $38,05 \%, 23,06 \%$ e $30,49 \%$, respectivamente para as Colheitas 2, 3, 4 e 5) no período em que este grupo de própolis foi colhido na época da precipitação média e baixa. A temperatura não entra como uma variável importante porque é praticamente a mesma para todas as amostras.

Foi observado, nesta pesquisa, que, além de os constituintes químicos da própolis variarem de acordo com o período de colheita, também foi verificado que de uma colméia para outra também há diferenças significativas. Isso também foi verificado no trabalho desenvolvido por IKEGAKI (2001), onde abelhas colocadas em um mesmo apiário produziram própolis de constituição química diferente. Este fato, provavelmente decorre por as abelhas terem, no código genético, um ou mais grupos de genes que codifique a informação, sugerindo o tipo de vegetação que deva ser visitada. É possível supor, desta maneira, que, mesmo abelhas habitando locais completamente distintos, apresentem o mesmo comando genético que as faça procurar determinadas espécies de plantas, originando própolis de mesma composição. PARK et al. (2000) encontraram resultados sugerindo a existência de uma maior diversidade de própolis nas regiões Sul e Nordeste do Brasil, na mesma proporção que a vegetação destas regiões também variam, confirmando os dados encontrados na própolis encontrada na região do Brejo Paraibano, onde houve formação de 2 grupos, diferenciados em função da precipitação ocorrida no local de acordo com época da colheita, influenciando no teor de cera e nos compostos bioativos da própolis.

Os dados analisados indicam que as plantas da região estudada apresentam uma maior disponibilidade de resina no período do inverno e, conseqüentemente, produção de uma própolis com maiores teores de compostos bioativos em sua composição. O teor de flavonóides, cinzas, cera e perdas por dessecação podem servir como alguns parâmetros básicos para a caracterização e ou composição da própolis (GARCIA et al., 2001). Para a determinação de flavonóides, observou-se que o espectro de absorção variou entre 0,014 (Colheita 3) e 0,033 (Colheita 4), com seus respectivos teores de flavonóides variando entre 0,19 -0,52\%. Nestas análises, observou-se que as amostras que apresentaram, maior absorbância $(0,470$ de leitura para determinação de fenóis - Colheita 1; e 0,033 de leitura 


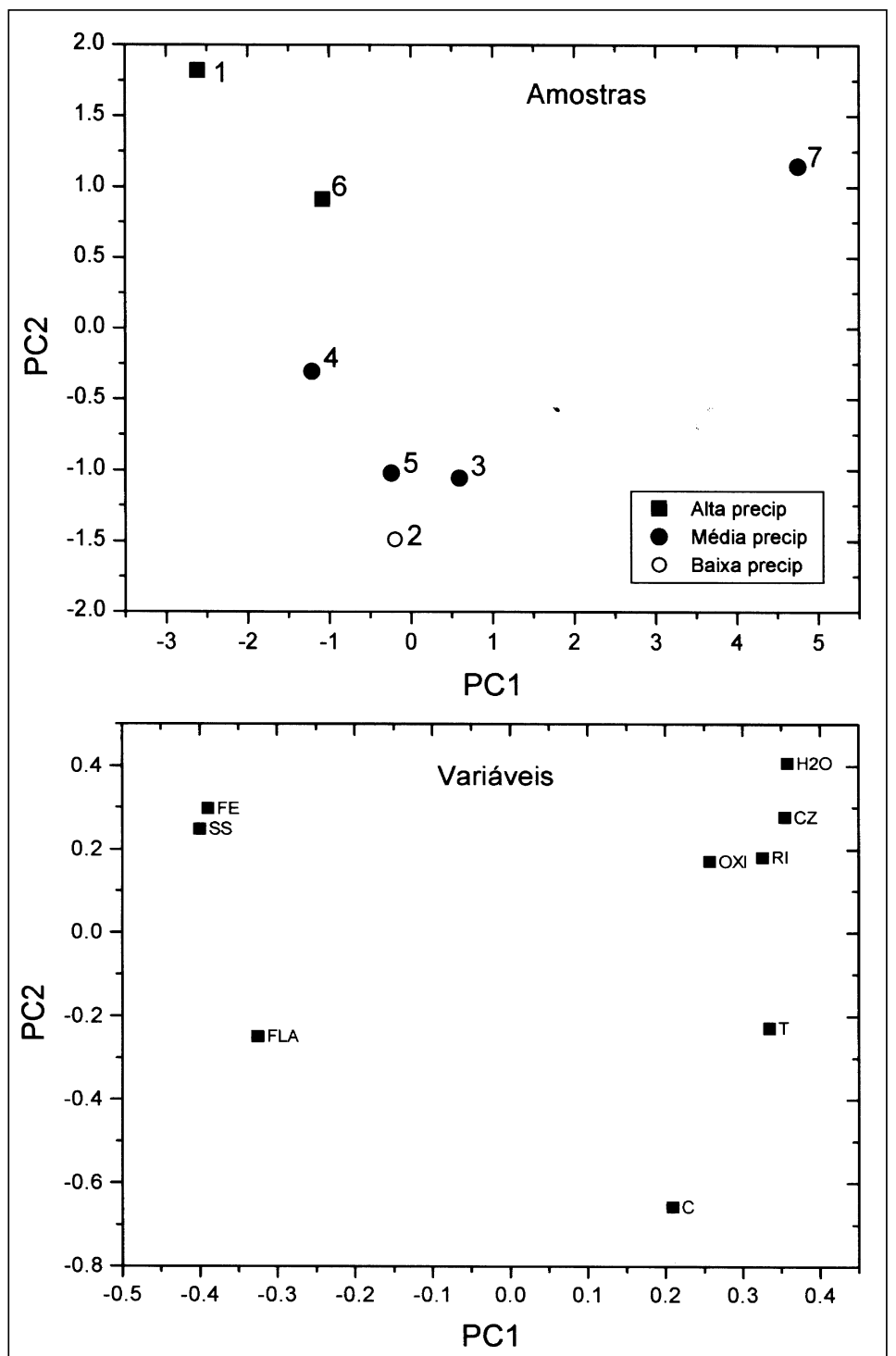

Figura 1 - Comportamento de dispersão dos componentes principais das amostras de própolis coletadas no Estado da Paraíba, de acordo com as variáveis: umidade (H2O), cinzas (CZ), resíduos insolúveis (RI), cera (C), sólidos solúveis (SS), fenóis (FE), flavonóides (FLA), atividade antioxidante (OXI), temperatura ambiente (T) e precipitação pluviométrica. Período de julho de 2001 a maio de 2002, Areia - PB.

para determinação de flavonóides - Colheita 4) apresentaram, conseqüentemente, maior quantidade de fenóis $(8,13 \%)$ e flavonóides $(0,52 \%)$. Tal teoria também é confirmada por KOO \& PARK (1996), que encontraram um maior teor de flavonóides, $6,35 \mathrm{mg} \mathrm{mL}^{-1}$ para uma maior leitura, 0,54 (absorbância a 290nm), e um menor teor de flavonóide, $1,25 \mathrm{mg} \mathrm{mL}^{-1}$, para uma menor leitura, 0,13 (absorbância a 290nm). No entanto, os extratos etanólicos de própolis deste trabalho não inibiram o crescimento de Candida albicans e Staphylococcus aureus, demonstando que os compostos bioativos das amostras não têm atuação antibiótica. Resultados parecidos foram encontrados por IKEGAKI (2001) e, segundo ele, para os dois microrganismos testados nesse trabalho, a própolis provavelmente tem uma atuação mais como uma barreira física do que propriamente como uma proteção biológica. Segundo MARCUCCI (1996), a própolis, assim como os outros produtos das abelhas, possui composição variada de acordo com a flora e as condições sazonais da área. Interessante relatar que as resinas coletadas pelas abelhas na preparação da própolis, mesmo em regiões diferentes, apresentaram compostos de fenóis e flavonóides que não respondem ao controle do crescimento dos microorganismos estudados, verificando a importância de se conhecer detalhadamente os compostos ativos da própolis para a determinação de suas características para sua utilização no controle medicinal sobre os diferentes microrganismos existentes.

\section{CONCLUSÕES}

A própolis da abelha africanizada (Apis mellifera L.) colhida em diferentes épocas do ano na microrregião do Brejo Paraibano, assim como própolis oriundas de diferentes famílias de abelhas, apresenta diferentes valores para a composição bromatológica e bioativa.

Própolis amostradas nos períodos de maior precipitação apresentam melhores valores para compostos bioativos. Não foi verificada a atividade antimicrobiana da própolis sobre Candida albicans e Staphylococcus aureus.

\section{REFERÊNCIAS}

AGA, H. et al. Isolation and identification of antimicrobial compounds in Brazilian propolis. Biosicience, Biotechnology and Biochemistry, Japan, v.58, p.945-946, 1994.

BANKOVA, V. S. et al. Chemical composition and antibacterial activity of Brasilian propolis. Zeitschrift fur Naturfosrschung, Tübingen v.50c, n.3-4, p.167-172, 1995. 
BRASIL. Ministério da Agricultura. Anexo VI - Regulamento Técnico para Fixação de Identidade e Qualidade de Própolis. Brasília, DF: Ministério da Agricultura, 2002. Capturado em 20 Out. 2002. Online. Disponível na Internet http://www.agricultura.gov.br/das/dipoa/instnorm03_propolis6.htm.

ENCICLOPÉDIA DOS MUNICÍPIOS PARAIBANOS., João Pessoa: UNIGRAF - PB, 1987. p.46.

FERNANDES JÚNIOR, A. et al. Estudo da Atividade Antimicrobiana de Própolis Obtidas em Regiões Distintas do Brasil. In: CONGRESSO BRASILEIRO DE APICULTURA, 12 ., 1998, Salvador. Anais... Salvador-BA: CBA/FAABA, 1998. 248p. p. 193.

FRANCO, T. T.; KUREBAYASHI, A. K. Isolamento de princípios ativos da própolis por cromatografia em papel bidimensional e doseamento espectrofotométrico. Revista do Instituto Adolfo Lutz., São Paulo, SP, v.46, n.1/2, p.81-86, 1986.

GARCIA, J.; et al. Produção de própolis em colônias de Apis mellifera africanizadas pelas técnicas convencional de raspagem e coletor de própolis inteligente. Maringá, PR. Anuário 1999/2000. Capturado em 30 de Nov. 2001. Online. Disponível na Internet http://www.cca.uem.gov/anu4600. htm.

GHISALBERTI, E. L. Propolis: a review. Bee World, Cardiff - País de Gales, v.60, p.59-84, 1979.

GREENAWAY, W. et al The composition and plant origins of propolis: a report of work at Oxford. Bee World, Cardiff País de Gales, v.71, p.107-118, 1990.

HAMMERSCHMIDT, P. A.; PRATT, D. E. Phenolic antioxidants of dried soybeans. Journal of Food Science, Chicago, v.43, p. 556-559,1978.

IKEGAKI, M. Determinação da qualidade de própolis de Apis mellifera africanizada da região sul do Brasil: avaliação de algumas propriedades físico-químicas e biológicas da própolis. 74f. 2001. Tese (Doutorado em Ciência de Alimentos), Curso de Pós-graduação em Ciência de Alimentos, Faculdade Engenharia de Alimentos, Universidade de Campinas, UNICAMP, SP.

KOO, M. H.; PARK, Y. K. Investigação do teor de flavonóides nas própolis comerciais. Revista Brasileira de Apicultura, Guarulhos, SP, ano VI, n.13, p.6-71, 1996.

LABBE, C.; et al. Secondary metabolites from Chilean Baccharis species. Journal of Natural Products, Washington n.49, p.517, 1986.

MARCUCCI, M.C. Zootécni: chemical composition, biological properties and therapeutic activity. Apidologie, Les Ulis Cedex, v.26, n.2, p.83-99, 1995.

MARCUCCI, M. C. Propriedades biológicas e terapêuticas dos constituintes químicos da própolis. Química Nova, São Paulo, SP, v.19, n.5, 1996.

MARCUCCI, M. C.; CUSTÓDIO, A. R. Análise de própolis. Campinas: NATURALAB, 2002. 25p.

MATSUNO, T. A new clerodane diterpenoid isolated from propolis. Zeitschrift fur Naturforschung, Tübingen, n.50c, p.93-97, 1995.

MIYATAKA, H.; et al. Evaluation of propolis. 1. Evaluation of Brazilian and Chinese propolis by enzymatic and physicochemical methods. Biology Pharmacology Bull., Tokyo, v.20, n.5, p.496-501, 1997.

PARK, Y. K. et al. Classificação das própolis Brasileiras a partir de suas características físico-químicas e propriedades biológicas. Mensagem Doce, São Paulo, n.58, Mai, 2000.

PARK, Y. K. et al. Comparação das características físicoquímicas das própolis produzidas na região sub-tropical da América do Sul: evidência fitoquímica de sua origem botânica. Mensagem Doce, São Paulo, n.61, Mai, 2001.

PRATT, D. E.; BIRAC, P. M. Source of antioxidant activity of soybeans and soy products. Journal Food Science, Chicago, v. 44 , p. $1720-1722,1979$.

PRATT, D. E.; WATTS, B. M. The antioxidant activity of vegetable extracts. I: Flavone aglycones. Journal Food Science, Chicago, v. 29, p. 27-31, 1964.

SAEG. Sistemas para análises estatísticas; Versão 8.0. Viçosa - MG: Fundação Arthur Bernardes, 2000.

SFORCIN, J. M. et al. Efeito da sazonalidade sobre a atividade antifúngica da própolis. In: CONGRESSO BRASILEIRO DE APICULTURA, 12., 1998, Salvador. Anais...Salvador-BA: CBA/FAABA, 1998, 248p. p.193.

SILVA, D.J. Análise de alimentos. 2. Ed. Viçosa, 1998, 166p.

VELOSO JÚNIOR, J. F. Análise da precipitação na microrregião "Brejo Paraibano" como suporte ao planejamento agrícola. 36f. 2000. Monografia (Graduação em Agronomia), Centro de Ciências Agrárias, Universidade Federal da Paraíba. 